\title{
La guerra de Argelia y la Argentina. Influencia e inmigración francesa desde 1945
}

\author{
Mario Ranaletti \\ Institut d'Études Politiques de Paris \\ Centre d'Histoire de Sciences Po
}

Este trabajo aborda la cuestión de la presencia e influencia francesa en la sociedad argentina entre 1955 y 1976, en especial en el ámbito militar y católico. Dos cuestiones son tratadas en este artículo. En primer término, se analizan dos momentos de una presencia inmigrante de más larga data como la francesa: la llegada de fugitivos con cargos por inteligencia con el ocupante alemán, y el arribo de emigrados y fugitivos como resultado de la independencia de Argelia. En segundo lugar, se relacionan estos hechos con la construcción del terrorismo de Estado implementado en Argentina a partir de 1974.

Palabras Clave: Terrorismo de Estado, O.A.S. (Organisation de l'Armée secrète), Peronismo, Guerra de Argelia (1954-1962), Doctrina de la guerra revolucionaria.

This paper approaches the question of the French presence and influence in the Argentine society between 1955 and 1976, specially, in the military and catholic spheres. Two questions are treated in this article. First, it analyzes two moments of the French migration process in Argentina in the long run: the fugitives' arrival --with charges for intelligence with the German occupant--, and the émigrés and fugitives' arrival as result of the Algeria's independence. Secondly, these facts are related to the construction of the State terrorism implemented in Argentina since 1974.

KeYwords: State terrorism, O.A.S. (Secret Army Organisation), Peronism, Algeria's war, Revolutionary war doctrine.

\section{Introducción: la Argentina, un país abierto a todos ${ }^{1}$}

Según el Preámbulo de su Constitución, la Argentina es un país abierto a "todos los hombres del mundo que quieran habitar el suelo argentino", sin

1 Las principales ideas contenidas en este artículo fueron discutidas en el Seminario del Dr. Carlos Cansanello en el Instituto Ravignani de la Facultad de Filosofía y Letras de la Universidad de Buenos Aires; agradezco los comentarios del Dr. Cansanello y de los asistentes. Una primera versión de este trabajo fue presentada en el X Encuentro de Latinoamericanistas Españoles, "Identidad y multiculturalidad: la construcción de espacios iberoamericanos", realizado en la Universidad de Salamanca, entre los días 13 y 14 de mayo de 2004. 
distinción de raza, ideología o religión. Después de la colonización española y de la independencia, la Argentina conformó su estructura social y poblacional a partir de diferentes olas migratorias internacionales e internas. Este proceso se completó con el exterminio y la marginación de la población indígena originaria, desplazada primero por la implantación europea y luego por la expansión territorial de sus herederos "criollos". Esta reconfiguración espacial y humana de la joven nación creó también sus propios mitos: del "crisol de razas", de la "europeización" y de la "tierra prometida", los cuales se instalaron en el imaginario social con gran facilidad, sobre todo gracias a la educación pública. La Argentina ha honrado esa declaración, incluida en el Preámbulo de su Constitución, recibiendo a personas provenientes de los más diversos puntos del planeta y por las más variadas razones. Las catástrofes políticas, religiosas y económicas del viejo continente expulsaron a campesinos y trabajadores pobres del entonces subdesarrollado sur europeo, judíos perseguidos por todas las variantes del tenaz antisemitismo europeo, anarquistas temporalmente derrotados, empresarios (schumpeterianos, unos; simples piratas de nuevo cuño, otros) y criminales de todas las guerras europeas huyendo del cambio de situación. A partir de 1945, al igual que los Estados Unidos, la Unión Soviética o Gran Bretaña, la Argentina se convirtió en un destino interesante para muchos responsables, ideólogos y "técnicos" de los derrotados totalitarismos en la Segunda Guerra Mundial. En lo que respecta al caso argentino, apellidos como Kutschmann, Mengele o Eichmann simbolizan el aspecto más repudiable de esta historia. Fiel a la línea planteada por el Preámbulo de la Carta Magna, los diferentes gobiernos de la Argentina no discriminaron a estos personajes, abriendo las fronteras incluso a muchos franceses aliados del poder nazi; la historia se repetiría al final de la guerra de Argelia. Para esta investigación, que ha comenzado en la Argentina y se desarrolla actualmente en Francia, se han consultado fundamentalmente archivos diplomáticos y militares de ambos países. ${ }^{2}$

2 SHAT (Service historique de l'Armée de Terre), Archives sur la guerre d'Algérie, Series: 1 H, 1 T, 12 T; Ministère des Affaires Étrangères, Archives Diplomatiques (en adelante, MAE-AD), Archives du Quai d'Orsay, Serie B-Amerique 1952-1963 y Serie Amérique 1964-1970, sub-serie Argentine; MAE-AD, Centre des Archives Diplomatiques de Nantes, Consulado de Francia en Buenos Aires, Serie 1957-1966; MAE-AD, Archives du Quai d'Orsay, Serie Europa 1961-1970, sub-serie España 1961- 1970; MAE-AD, Archives du Quai d'Orsay, Europa 1944-1966, sub-serie España; Ejército Argentino, Dirección General del Personal, Archivo Histórico del Ejército, 18.957: Mom, Manrique Miguel (Infantería), 15145: Tibiletti, Pedro Alfredo (Infantería), 15107: Hure, Nicolás Cándido (Artillería), 15119, Rosas, Carlos Jorge (Ingenieros), 18.167: Señorans, Eduardo Argentino; 
Este trabajo constituye un avance de la investigación para la tesis de doctorado sobre la presencia e influencia francesa en la sociedad argentina entre 1955 y 1976, en especial en el ámbito militar y católico. Dos cuestiones son tratadas en el artículo: en primer término, se analizan dos momentos de la presencia inmigrante francesa de más larga data; luego, se presentan sus vínculos con los orígenes del terrorismo de Estado implementado en la Argentina a finales del tercer gobierno peronista. Nuestro trabajo intenta reconstruir, por un lado, un movimiento migratorio entre Argelia, España, Francia y la Argentina, y, por otro lado, la circulación de ideas que alimentarían la formación de un imaginario en torno a la cuestión de la protesta y de la violencia política en la Argentina durante el período 1955-1976. En lo relativo al movimiento de personas, consideraremos brevemente primero la fuga hacia la Argentina de personas que han colaborado en Francia con la ocupación alemana, pues serán estos "exiliados" quienes abrirán el camino para futuros arribos de personas con un background similar. En segundo lugar, introduciremos la emigración producida como consecuencia del fin de la guerra de Argelia; en este caso, se trata de un proyecto de instalación de colonos argelinos y del ingreso de terroristas de la Organisation de l'Armée secrète (OAS). Finalmente, presentaremos el contexto argentino de inserción y un avance de las relaciones que se establecieron entre franceses y argentinos. El arribo de franceses a la Argentina no es significativo numéricamente; por el contrario, sí es importante su contribución al corpus de ideas que conformarán y sustentarán el terrorismo de Estado implementado por la última dictadura militar (1976-1983). Se insertará después de las conclusiones un esquema de análisis como síntesis de lo expuesto.

El aporte francés fue capital en la elaboración del discurso legitimador empleado por la dictadura para justificar tanto en el interior de las Fuerzas Armadas como frente a la sociedad el accionar represivo desplegado. Como intentaremos explicarlo sucintamente más adelante, el aporte francés despertó un gran interés en el ámbito castrense y del tradicionalismo católico argentino por su lenguaje adaptado a la Guerra Fría (modernización), su empleo de conceptos de las ciencias sociales (pseudocientificidad) y su tono

Archivo Histórico del Ejército, Boletín Público del Ministerio de Ejército, 1953-1966; Archivo Histórico del Ejército, Boletín Reservado del Ministerio de Ejército, 1955-1958; Archivo Histórico del Ejército, Boletín Reservado de la Secretaría de Guerra, 1958-1966; Archivo Histórico del Ejército, Boletín Confidencial de la Secretaría de Guerra, 1958-1966; Presidencia de la Nación, Biblioteca de la Escuela Nacional de Inteligencia, Ejército Argentino, Reglamento RC-9-1 Reservado: Operaciones contra elementos subversivos, Buenos Aires, Instituto Geográfico Militar, 1977; Archivos de "La Cité Catholique", Paris. 
premonitorio y apocalíptico (catolicismo). En un intrincado entramado silogístico, todo esto se encadenaba como proposiciones lógicas irrefutables su fundamento último se hallaba en la religión católica-, dando origen a un esquema de pensamiento que puede resumirse de la siguiente manera: toda protesta social encubría, detrás de las reivindicaciones sociales, económicas o políticas, una acción tendiente a debilitar al occidente "católico"; el objetivo era subvertir el orden establecido para acabar con la civilización "occidental y cristiana". Lo dicho permitía poner en práctica todo tipo de acciones, aun las más crueles e inhumanas, para defender a la "civilización" amenazada de muerte. Este esquema fue adoptado y adaptado a la situación argentina por quienes serían los líderes de la dictadura (militares y civiles), en el marco de su formación militar superior y en estrecha relación con determinados grupos del tradicionalismo católico a partir de 1955. La contribución francesa se anclaba en varios componentes históricos del imaginario católico-militar argentino, sobre todo, en la idea del "enemigo interno". La matriz francesa hizo un aporte decisivo en:

a) la operación ideológico-discursiva de transformar a todo activista político en un "subversivo";

b) la consolidación en el imaginario militar argentino de la idea de que una tercera guerra mundial ya había comenzado (algo anticipado por Perón), de la cual los fracasos colonialistas franceses (Indochina, Suez, Argelia) y la Revolución Cubana eran la confirmación;

c) la idea de que toda protesta social era el resultado de la acción encubierta del "comunismo internacional", fuera cual fuere su signo político y su objetivo;

d) la idea de que la Guerra Fría era un enfrentamiento entre "civilizaciones": el Occidente capitalista y católico frente a la Unión Soviética, empeñada en destruir dicha civilización occidental para instalar el "materialismo ateo", en una extemporánea recuperación del pensamiento político medieval.

Entendemos la intensificación de la influencia francesa y los comienzos del terrorismo de Estado no como una relación de causalidad, sino como una coincidencia espacio-temporal y una interacción mutua. ${ }^{3}$ Con

3 Esta interpretación del complejo período histórico que se abre en la Argentina con el derrocamiento de Perón cobra fuerza en Francia, particularmente a partir de los trabajos de los periodistas Pierre Abramovici y Marie-Monique Robin; Abramovici, Pierre: "Argentine. L'autre sale guerre d'Aussaresses“, Le Point, Paris, 1500, 15 de junio de 2001, págs. 26-34; Robin, Marie-Monique: Escadrons de la mort, l'école française, Ediciones La Découverte, Paris, 2004. 
respecto a los franceses, los indicios que hemos encontrado en nuestra investigación y la lectura de los trabajos que nos precedieron nos orientan a considerar su influencia como determinante en la implantación de lo que llamaremos "formación continua" en extremismo ideológico — que a la postre funcionará eficazmente en la educación reaccionaria de los cuadros implicados en el terrorismo de Estado-, más que una participación directa en estos hechos. ${ }^{4}$

\section{El exilio argentino de los franceses en la segunda posguerra}

No es posible estudiar este tema sin hacer una breve mención a la historiografía sobre este tipo de "exilios", pues el arribo al Río de la Plata de numerosos colaboracionistas franceses nos remite a otro tema más estudiado: la Argentina como refugio de criminales de guerra nazis. Comenzaremos por una revisión crítica y somera de la asociación entre este fenómeno y el peronismo por entonces gobernante. Muy a menudo, la interpretación del peronismo como un "aliado" o "derivación natural" de la extrema derecha europea, o su definición a la ligera como "fascismo" de tipo latinoamericano y de Perón como un "fascista", ha perturbado las miradas y opiniones de historiadores, politólogos, sociólogos, políticos y periodistas. ${ }^{5}$ No obstante, la lectura de los trabajos de Uki Goñi ${ }^{6}$ sobre la llegada de criminales nazis durante las dos primeras presidencias de Juan Domingo Perón parecería bastar para sostener la validez de esta interpretación.

4 Esta línea de análisis ha sido planteada por el coronel Prudencio García en su trabajo sobre el militarismo argentino, retomando en parte el estudio pionero de Alain Rouquié; además, Franck Lafage ha avanzado en el mismo sentido. García, Prudencio: El drama de la autonomía militar. Argentina bajo las Juntas Militares, Alianza, Madrid, 1995; Lafage, Franck: L'Argentine des dictatures 1930-1983. Pouvoir militaire et idéologie contre-révolutionnaire, L'Harmattan, Paris, 1991; Rouquié, Alain: "La tentación del catolicismo nacionalista en la República Argentina", en: Rouquié, Alain: Autoritarismos y democracia. Ensayos de política argentina, Hachette, Buenos Aires, 1994, págs. 83-139.

5 Esto es particularmente llamativo en Francia, donde sigue vigente la interpretación del peronismo difundida por el antiperonismo triunfante a partir de 1955, en especial en la gran prensa y la educación nacional. Para una de las más interesantes interpretaciones de las relaciones entre el peronismo y el totalitarismo europeo, se puede consultar (a pesar de los problemas de traducción al español que presenta la edición) Rein, Raanan: Entre el abismo y la salvación. El Pacto Perón-Franco, Prólogo de Samuel Amaral, Ediciones Lumière, Buenos Aires, 2003.

6 Goñi, Uki: Perón y los alemanes. La verdad sobre el espionaje nazi y los fugitivos del Reich, Sudamericana, Buenos Aires, 1998; Goñi, Uki: La auténtica Odessa. La fuga nazi a la Argentina de Perón, Paidós, Buenos Aires, 2002. 
En lo relativo a los franceses, las investigaciones realizadas hasta ahora sobre los primeros años de la posguerra muestran cuán tibios fueron los esfuerzos y magros los resultados obtenidos en repatriar a los condenados a muerte de origen francés que se refugiaron en la Argentina (especialmente en Buenos Aires y Mendoza). ${ }^{7}$ De este modo, el lejano país del sur servía como "válvula de escape" para la convulsionada escena política francesa, envuelta en la debacle socio-económica y en un ajuste de cuentas que muchos temían se convirtiera en una guerra civil. La poca voluntad de las autoridades políticas de ambos países en intensificar las medidas tendientes a someterlos a la justicia se debió, en primer lugar, a las razones de política interna francesa mencionadas; en segundo lugar, varios de estos individuos habían logrado incorporarse al aparato estatal y productivo argentino, de lo cual se esperaba sacar provecho a ambos lados del Atlántico. La importante colonia francesa ya instalada en el país se ocupó de brindar apoyo y una buena acogida a sus compatriotas, transformándose en un actor central de esta historia. Según lo hemos podido constatar en los archivos diplomáticos franceses consultados, la embajada en la Argentina hizo un seguimiento del movimiento migratorio. ${ }^{8}$ Para el periodista Éric Conan, "al final de los años cuarenta, huyendo de la depuración, cientos de franceses desembarcan en Buenos Aires. En esta ciudad, que les recuerda mucho a París, nadie presta demasiada atención a su pasado. Y no corren el riesgo de ser extraditados [no existe un tratado binacional]. Algunos reharán su vida, adquiriendo cierta notoriedad social. Otros vegetarán". ${ }^{9}$ Así, los "exiliados" franceses encontraron en la Argentina la posibilidad de pasar desapercibidos en un país lejano y atractivo, además de un refugio seguro donde muchos comenzarían una nueva vida y otros aguardarían el momento propicio para retornar.

7 Quatrocchi-Woisson, Diana: "Relaciones con la Argentina de funcionarios de Vichy y de colaboradores franceses y belgas, 1940-1960", Estudios Migratorios Latinoamericanos, 43, Buenos Aires, 14, diciembre 1999, págs. 211-238; Ranaletti, Mario: "Une présence française fonctionnelle: les militaires français en Argentine après 1955", Matériaux pour l'histoire de notre temps, 67, Nanterre, Pour une histoire de l'Exil français et belge, julio-septiembre 2002, págs. 104-106; Rolland, Denis: "L'Argentine,'terre" idéale de l'exil et de l'émigration européenne francophones ?", Matériaux pour l'histoire de notre temps, 67, Nanterre, Pour une histoire de l'Exil français et belge, julio-septiembre 2002, pág. 111.

8 MAE-AD, Centre des Archives Diplomatiques de Nantes, Consulado de Francia en Buenos Aires, Série 1957-1966, 69 CA II.2 Français d'Argentine: 1956-1966, dossier 2: Réfugiés politiques français (1959-1968).

9 Conan, Éric: “La cavale des maudits”, L’Express, Paris, 12 de agosto de 1993, págs. 39-40. 
En cuanto a la actividad que los exiliados desarrollaron en la Argentina, la mayoría intentó no destacarse públicamente. Sin embargo, algunos casos alcanzaron cierta notoriedad, en especial en el ámbito de la enseñanza universitaria y el periodismo como Jean Azéma, ${ }^{10}$ Albert Falcionelli ${ }^{11}$ o Jacques Marie de Mahieu. ${ }^{12}$ Quizás el caso más significativo fue el de Jean-Pierre Ingrand, representante del ministro del Interior del gobierno colaboracionista francés ante las autoridades alemanas durante la ocupación de Francia (julio de 1940-enero de 1944). Presidente de la Alianza Francesa de Buenos Aires hasta su fallecimiento en 1992, Ingrand fue el responsable administrativo de una parte del proceso de deportación de franceses hacia los campos de trabajo y de exterminio alemanes. ${ }^{13}$

La sanción en 1959-1960 de una amnistía generosa por parte del gobierno francés para causas judiciales en colaboración con el enemigo nos aporta interesantes informaciones sobre los "refugiados políticos" galos en

10 Redactor de la revista Je suis partout, se suma al equipo de la publicación nacionalista Azul y Blanco; Cf. MAE-AD, Centre des Archives Diplomatiques de Nantes, Consulado de Francia en Buenos Aires, Série 1957-1966, 69 CA II.2 Français d'Argentine: 1956-1966, dossier 2: Réfugiés politiques français (1959-1968), Comunicación de Christian de Marguerie (embajador en Argentina) al Ministro de Relaciones Exteriores, Direction des Conventions Administratives et Affaires Consulaires, nota $\mathrm{n}^{\circ} 130,8$ de febrero de 1968 .

11 Ex funcionario del Office français d'Information en Madrid. El Office d'information fue creado por el gobierno de Pétain el 20 de diciembre de 1940, y su función era recabar información y hacer propaganda a favor de la Francia colaboracionista. Ver: MAE-AD, Europe 1944-1966, sub-serie Espagne, Sous-Direction d'Europe Méridionale, Corps diplomatique et consulaire, Représentation de la France en Espagne: Délégation du Gouvernement français à Madrid, consulats et agences consulaires, anciens agents du gouvernement de Vichy restés à Madrid, agosto 1944-junio 1949, 1, Télégramme de M. Chauvel , 26 mayo de 1945. Falcionelli desarrollará una extensa carrera como profesor de Historia en la Universidad de Cuyo, colaborando con la SIDE y la delegación argentina de la CIA en los años sesenta. Además de los indicios sobre el particular señalados por uno de sus discípulos, el Dr. Cristian Buchrucker en el trabajo ya citado, los vínculos entre Falcionelli, la SIDE y la CIA aparecen mencionados en las memorias de uno de los agentes de la CIA destacados en Buenos Aires a partir de 1958; Cf. Smith, Joseph Burkholder: Portrait of a Cold Warrior. Second Thoughts of a Top CIA Agent, Ballantine Books, New York, 1976, págs. 361-363.

12 Este sociólogo y ex colaboracionista llegó a la Argentina en 1946. Se incorporó como docente en la Universidad Nacional de Cuyo (provincia de Mendoza), una de las regiones argentinas preferidas por los inmigrantes franceses desde el siglo XIX. Fue uno de los mentores de la fracción de extrema derecha del grupo Tacuara y su libro El Estado comunitario tuvo un gran impacto en los años sesenta. Ver: Bardini, Roberto: Tacuara. La pólvora y la sangre, Editorial Océano, México, 2002, pág. 36; Girbal de Blacha, Noemí: Armonía y contrapunto intelectual: Dinámica social (1950-1965), en: http://www.argiropolis.com.ar.

13 Ingrand no fue "molestado" judicialmente e incluso se entrevistó con de Gaulle —a pesar de las recomendaciones contrarias del embajador francés en Buenos Aires- en ocasión de la visita oficial del Presidente francés en 1964, según Claude Cymerman, empleado de la Alianza francesa de Buenos Aires e intérprete del presidente de Gaulle durante su visita a la Argentina; Cymerman, Claude, Entrevista personal, Paris, 2 de octubre de 2003. 
la Argentina. Una vez conocida esta decisión política, los franceses residentes en la Argentina se pusieron en contacto con las autoridades consulares para interiorizarse sobre los requisitos para sumarse a la amnistía. Gracias al procedimiento implementado (solicitud de inclusión en la amnistía vía consulado local) podemos conocer muchos datos sobre los solicitantes: ${ }^{14}$ en la mayoría de los casos, la amnistía fue acordada, los informes elaborados por el consulado muestran que, por lo general, los franceses evitaron inmiscuirse en la vida política argentina. Así, el retorno se convertía en una posibilidad concreta.

En síntesis, por su historia previa, por sus intereses económicos y estratégicos, la Argentina de Perón era un buen lugar para los nostálgicos del "Nuevo Orden" derrotado, retomando la feliz expresión de Cristian Buchrucker. ${ }^{15}$ Los proyectos industriales y tecnológicos del peronismo, la enseñanza universitaria y del francés, el periodismo, el comercio y la industria fueron las actividades privilegiadas por estos franceses para recomenzar una vida en sociedad lejos de la justicia de su país. En lo relativo a la recepción de criminales de guerra por parte de la Argentina, entendemos que debería darse mayor importancia al profundo arraigo de la extrema derecha y la presencia de fuertes rasgos autoritarios en la cultura política argentina, en especial a partir del ciclo de protesta social y violencia política de 1909-1921 y de la crisis de 1930.

\section{La guerra de Argelia y los franceses en la Argentina}

La última guerra colonial francesa tuvo un impacto considerable en la sociedad argentina, cuyas marcas pueden hallarse en la extrema derecha, el catolicismo, la izquierda universitaria o las organizaciones guerrilleras. Aunque con menor intensidad y consecuencias diferentes, la guerra de

14 Nombre verdadero, nombre falso utilizado, domicilio y actividad desempeñada en Argentina, naturaleza de las acusaciones, tribunal francés que tramita la causa, opinión del Ministerio de Justicia francés y/o de la Embajada francesa en Argentina sobre la conveniencia de permitir que el solicitante se acoja a la amnistía, en: MAE-AD, Centre des Archives Diplomatiques de Nantes, Consulado de Francia en Buenos Aires, Serie 1957-1966, 69, CA II.2 Français d'Argentine: 1956-1966, dossier 2: Réfugiés politiques français (1959-1968), Direction des Conventions Administratives et Affaires Consulaires.

15 Buchrucker, Cristian: “Los nostálgicos del 'Nuevo Orden’ europeo y sus vinculaciones con la cultura política argentina de la postguerra", proyecto de investigación de Ia CEANA (Comisión para el Esclarecimiento de las Actividades del Nazismo en la República Argentina), Buenos Aires, febrero 1998, pág. 1. 
Argelia (1954-1962) generó también distintas opiniones, solidaridades y pasiones en la sociedad argentina como años antes lo había hecho (y lo seguía haciendo) la Guerra Civil española. Menos numerosa, menos arraigada y demasiado proclive a destacar su singularidad (si esto conviene a sus intereses económicos y sociales), la colectividad francesa local no se transformó en un actor clave en los debates que generaba la descolonización del Maghreb, como sí lo habían hecho los españoles en el momento de su enfrentamiento fratricida. Sin embargo, muchos ámbitos de la vida cultural y política argentina se vieron profundamente afectados, desde la formación militar superior hasta la enseñanza del francés, pasando por el cine y por la lucha independentista argelina.

El 19 de marzo de 1962 los acuerdos celebrados en Evian entre los representantes del Frente de Liberación Nacional argelino y el gobierno del general de Gaulle pusieron fin a la presencia colonial francesa y a una guerra que se cobró más de un millón de vidas, en su mayoría civiles argelinos. La evacuación de la colonia imponía la repatriación de una gran cantidad de personas que abandonaban Argelia por temor a las represalias y por rechazo a la descolonización. Los llamados "franceses de Argelia", considerados ciudadanos de segunda por los metropolitanos, tuvieron que buscar nuevos horizontes. Los destinos privilegiados fueron dos: España - básicamente Alicante- y la Argentina ${ }^{16}$ Lejos de constituir un exilio "político", la salida de estos franceses de Argelia es un caso bien diferente. Para Jean-Jacques Jordi, "más que una simple repatriación, este movimiento puede considerarse como una verdadera migración, pues incluye los sentimientos de éxodo y exilio muy presentes en los individuos que la componen". ${ }^{17}$ Dos características presentaba la mayoría de los franceses que llegaban a la Argentina con la derrota del colonialismo en África del norte y en Extremo Oriente a cuestas: un furioso anticomunismo y un catolicismo exacerbado. Lo que permitió que los más comprometidos políticamente pudieran vincular fácilmente su pasado nordafricano con la nueva realidad argentina, no para soñar con la restauración del colonialismo, sino más bien para aggiornar discursos y retomar viejas costumbres, como la vida clandestina, los seudónimos, los informes apócrifos, la megalomanía, los contactos con el mundo militar y la "comunidad" de inteligencia y el espíritu de cruzada.

16 Palacio, Léo: Les Pieds-Noirs dans le monde, J. Didier, París, 1968, págs. 30-32.

17 Jordi, Jean-Jacques: De l'exode à l'exil. Rapatriés et Pieds-Noirs en France. L'exemple marseillais, 1954-1992, L'Harmattan, París, pág. 7, 1993. 
En 1963 se iniciaron las negociaciones tripartitas entre particulares y los dos Estados para concretar la instalación en la Argentina de un número importante de repatriados de Argelia. El gobierno francés no tenía soluciones para el problema de la reinserción de los franceses de Argelia, concentrado como estaba en detener una sangrienta posguerra colonial. Alentar una ola migratoria parecía la mejor opción para no sumar elementos de discordia a una situación interna que se volvía una vez más conflictiva. De este modo, según la historiadora Geneviève Verdo, "la organización de esta emigración constituía tanto un acto político como un acuerdo de orden económico [...]; a comienzos del mes de enero de 1964, un grupo de sesenta familias desembarca en el puerto de Buenos Aires". ${ }^{18}$ Nuevamente, como en el caso de los colaboracionistas, la Argentina se convertía en una válvula de escape para el gobierno francés. Durante los dos años siguientes, otros cinco grupos se agregarían, conformando un total de "ciento cincuenta familias oficialmente registradas en el marco de esta emigración". ${ }^{19} \mathrm{El} 19$ de octubre de 1964 se firmó el acuerdo entre los gobiernos, que incluía interesantes ventajas para los "colonos" ${ }^{20}$ Entre Ríos, Formosa (El Colorado), Chaco, Salta (Rosario de Lerma), Río Negro (Valle Azul) y San Juan fueron los lugares de destino asignados a las familias pieds-noir que desembarcaron en el puerto de Buenos Aires esperando encontrar tantas oportunidades como en Argelia, pero sin la presencia de los árabes. ${ }^{21}$ Pensado por el gobierno de

18 Verdo, Geneviève: Les Français d'Afrique du Nord en Argentine: Bilan provisoire d'une migration (1964-1988), Memoria de Maestría, Université de Paris I, Paris, 1989, págs. 34-39.

19 Verdo: Les Français..., pág. 13.

20 Del lado argentino, el compromiso consistía en facilitar las gestiones para la importación de bienes muebles y de capital, además de ofrecer: tierras libres en ventajosas condiciones, exención de derechos aduaneros, asistencia educativa y sanitaria, y libre disponibilidad y transferencia de divisas desde Francia, fijando límites máximos para las transacciones y las franquicias. Por su parte, el gobierno francés, se hacía cargo de los gastos de traslado de las personas y de sus bienes; además, concedería una ayuda económica en efectivo por familia para afrontar los primeros tiempos. No obstante, lo que se había pensado como una experiencia de colonización se convirtió en emprendimientos individuales. Del lado francés, la ignorancia casi total del medio en el cual se iban a instalar, la incompetencia de las autoridades consulares y de los franceses encargados de organizar la salida de los repatriados (bloqueo de sus fondos y obstáculos burocráticos french style), expectativas desmesuradas — para algunos, un nuevo "El Dorado"- y resabios colonialistas hicieron primar el desorden y la impericia. A todo esto se sumaron los errores cometidos por las autoridades argentinas a todo nivel. Se puede consultar: MAEAD, Archives du Quai d'Orsay, Série Amérique 1964-1970, Argentine, 177: Colonie et immigration française, octubre 1967-octubre 1970, Carta de Maurice Schumann, embajador de Francia, al Ministro de Relaciones Exteriores, 434/AS, 14 de octubre de 1970, tema: "Reconduction en 1971 de la Mission du B.D.P.A. en Argentine"; Santi, Isabel: "Evocando la emigración a la Argentina de los franceses Ìpieds noirsì de Argelia", Amérique latine Histoire et Mémoire. Les Cahiers ALHIM, 9, Université Paris VIII, Migrations en Argentine II, Paris, 2004.

21 Según uno de los testimonios recogidos en su investigación por Isabel Santi el artículo citado precedentemente. 
Illia como un relanzamiento de la política de colonización, los resultados iniciales han dejado un recuerdo agridulce en los expatriados.

No obstante, para algunos franceses de frondoso prontuario este acuerdo fue la discreta puerta de entrada al país: varios terroristas de la OAS lograron beneficiarse de las ventajas ofrecidas a los colonos. La periodista MarieMonique Robin mostró que los miembros y simpatizantes de la OAS recibieron los mismos beneficios que quienes se inscribieron en las sedes consulares y oficinas de migración francesas para incorporarse al proyecto franco-argentino de creación de colonias. Robin entrevistó a algunos de ellos, como Hervé Faure, Nicole y Michel Bésineau, y Bertrand de Perseval. ${ }^{22}$ Según Isabel Santi, el primer punto de reunión para los ex OAS fue Tacaaglé (provincia de Formosa, a $248 \mathrm{~km}$ de su capital), una antigua misión jesuítica. Otros, como el coronel Jean-Yves Gardes (responsable de la "organización de masas" de la OAS), el general Paul Gardy (último jefe máximo de la OAS) y el capitán Bertrand de Gorostarzu no necesitaron inscribirse en plan de colonización alguno para instalarse en la Argentina, una vez que el gobierno del general de Gaulle logró un acuerdo con la mayoría de los integrantes de la organización terrorista que había atentado varias veces contra su vida: ${ }^{23}$ les bastó con la ayuda de sus compatriotas y su prestigio

22 Faure es hoy el delegado en Argentina del tercer partido de Francia, el ultraderechista Front National de Jean-Marie Le Pen; en el pasado, este ex agricultor de Corrientes se convirtió en contratista de las Fuerzas Armadas argentinas para la provisión de equipos electrónicos. El matrimonio Bésineau tuvo una activa participación en la guerra de Argelia en tanto miembros de la OAS; además, la señora Bésineau es la hija del general Gardy (último jefe de la OAS) y ex pareja de Roger Delguedre (uno de los miembros de la OAS fusilados por terrorismo). En cuanto a de Perseval, mientras estaba detenido en la prisión de Fresnes por su participación en la OAS, las autoridades francesas le ofrecieron dinero y documentación para viajar a Argentina a cambio de abandonar la actividad terrorista, según su propio relato de los hechos. Todas estas informaciones fueron obtenidas por Marie-Monique Robin y han sido publicadas en Robin, Marie-Monique: Escadrons de la mort, l'école française, Editions La Découverte, París, 2004, cap. 22. Para algunas pistas sobre el seguimiento oficial de estas personas, ver: MAE-AD, Archives du Quai d'Orsay, Série Amérique 1964-1970, Argentine, 177: Colonie et immigration française, octubre 1967- octubre 1970, nota $\mathrm{n}^{\circ}$ 403/CH, 28 de septiembre de 1970; MAE-AD, Centre des Archives Diplomatiques de Nantes, Consulado de Francia en Buenos Aires, Serie 1957-1966, 69, CA II.2: Français d'Argentine: 1956-1966, dossier 2: Réfugiés politiques français (1959-1968), nota ${ }^{\circ} 249$ CM, 14 de marzo de 1963.

$23 \mathrm{El}$ acuerdo propuesto incluía el fin de la tolerancia franquista a las actividades de estos terroristas en España. Quienes aceptaron abandonar toda actividad conspirativa contra de Gaulle fueron amnistiados y poco tiempo después se les permitió volver a Francia; los que no aceptaron el acuerdo fueron inmediatamente expulsados de España hacia Venezuela, Paraguay, Uruguay, Argentina y Portugal. Roger Frey, ministro del Interior y artífice de la operación, designó a Michel Baroin (policía de la Direction de Sécurité du Territoire) para la tarea de convencer a los OAS con base en España. Cf. Blanquer, Jean-Michel: Michel Baroin, les secrets d'une influence, Plon, Paris, 1992, pág. 87; Kauffer, Rémi: OAS. Histoire d'une guerre franco-française, Editions du Seuil, Paris, 2002, págs. 388-389; Segura Valero, Gastón: A la sombra de Franco. El refugio español de los activistas franceses de la OAS, Ediciones B, Barcelona, 2004. 
como "especialistas" en contrainsurgencia. Los franceses desplazados por la descolonización se encontraron con una sociedad crispada por los avances sociales y económicos logrados por los trabajadores algunos años antes y en estado de agitación, por lo que creían eran signos de la presencia de un enemigo interno ${ }^{24}$ y la "expansión" de la "subversión" comunista en el cuerpo social. Este clima les era familiar: ellos también creían en los mismos fantasmas, e interpretaban la independencia de las colonias como el resultado de una maniobra orquestada por el "comunismo internacional" para destruir a la "civilización occidental y cristiana". Los que partían a una nueva aventura en tierras lejanas en el interior del país, como los colonos, fueron ajenos a los problemas políticos nacionales, pero quienes se instalaron en las grandes aglomeraciones (como Buenos Aires y Mendoza) rápidamente pudieron recuperar antiguos hábitos y prácticas.

Por ejemplo, en marzo de 1963, el coronel Jean-Yves Gardes y Alain Serrien, requeridos por la justicia de su país por su participación en la OAS, llegaron a Buenos Aires ${ }^{25}$ siendo recibidos por Albert Falcionelli (empleado de la Oficina francesa de Información bajo el gobierno de Vichy en Madrid), que además albergaría a Gardes en su domicilio particular. Falcionelli era un ferviente anticomunista que había llegado legalmente a la Argentina, y en 1950 adquirió la ciudadanía argentina. Fue un asiduo colaborador de la revista Verbo, órgano oficial de "La Ciudad católica", la filial argentina del grupo tradicionalista católico francés liderado por Jean Ousset al cual adhería Gardes en Francia. Durante su servicio en Argelia, Gardes fue el jefe del "Bureau d'Action psychologique" del Ejército francés, que tenía como órgano de difusión a la revista Contacts; esta publicación reproducía periódicamente artículos de la revista Verbe (de "La Cité Catholique" de Ousset) y era dirigida por el comandante Jean Cogniet, otro de los militares franceses ligados al grupo de Jean Ousset. Pero Gardes no fue el único. El general Paul Gardy llegó aproximadamente en la misma época, huyendo de la justicia francesa, después de una estadía en el País

24 Como lo mostró Sandra McGee Deutsch, éste era un viejo fantasma presente en el imaginario militar desde la época de auge del anarquismo. Ver McGee Deutsch, Sandra: Counterrevolution in Argentine, 1900-1932. The Argentine Patriotic League, University of Nebraska Press, Lincoln \& London, 1986; McGee Deutsch, Sandra: Las Derechas. The Extreme Right in Argentine, Chile and Brazil, 1890-1939, Stanford University Press, 1999.

25 MAE-AD, Centre des Archives Diplomatiques de Nantes, Consulado de Francia en Buenos Aires, Série 1957-1966, 69 CA II.2 Français d'Argentine: 1956-1966, dossier 2: Réfugiés politiques français (1959-1968); "Hora final de la OAS: Argoud ante sus jueces, Gardes en Buenos Aires", Primera Plana, Buenos Aires, 12 de marzo de 1963, págs. 15-16. 
Vasco (más precisamente, en San Sebastián). ${ }^{26}$ Gardy fue el único militar con rango de general que pudo esquivar la cárcel. La presencia de este militar francés en la Argentina no provocó mayores comentarios en la prensa del país, hasta su fallecimiento en un accidente automovilístico, el 27 de octubre de 1975. ${ }^{27}$ En mayo de 1963 llega Bertrand de Gorostarzu, ${ }^{28}$ que se unirá al matrimonio Bésineau (ya instalado en Tacaaglé) junto al capitán de corbeta Jacques Picquet (otro fugitivo de la Justicia) y Christian Disert, un pied-noir de Orán". ${ }^{29}$

Por varias razones, la Argentina de 1963 era un contexto sumamente favorable a las pretensiones de estos franceses desplazados y sobre quienes pesaban condenas a muerte, en varios casos. El país que encontraron era el que habían comenzado a construir los militares y sus aliados civiles en 1955, en nombre de la restauración de la libertad, de la democracia y de la recuperación económica, sumado a la brusca entrada en la Guerra Fría. Con el derrocamiento de Perón, la Argentina ingresó en una nueva etapa: la exclusión del mayor partido político nacional (primera causa de la violencia política), el ajuste de cuentas y recomposición de las relaciones con los Estados Unidos y la incorporación al esquema continental de defensa regido por ese país. La proscripción y persecución del peronismo impulsó una espiral de violencia que en realidad traducía un enfrentamiento de clases $^{30}$ y cuyo objetivo fundamental, más allá de toda retórica y clima de época, era revertir la redistribución de la riqueza que había tenido lugar durante los dos primeros gobiernos de Perón (1946-1955). Una burguesía atemorizada lanzó una frenética campaña anticomunista para poner en caja al activismo radical de los peronistas que poco a poco se transmutó en una trágica lucha en defensa de la "civilización occidental y cristiana". La incorporación de la Argentina a la Guerra Fría y al bloque regional orientado por la política exterior de los Estados Unidos sirvió para internacionalizar este conflicto

26 Veterano de Indochina, inspector general de la Legión Extranjera, condenado a muerte por contumacia por el Alto Tribunal Militar de París por atentar contra la seguridad el Estado, figura preponderante del golpe del 21 de abril de 1961, responsable de la rama Argelia-Sahara de la OAS, el general Gardy sustituyó al general Edmond Jouhaud como jefe de la OAS después de la independencia de Argelia y poco antes del derrumbe definitivo de la organización terrorista. Cf.: Vaïsse, Maurice: 1961, Alger, le putsch, Éditions Complexe, Bruselas, 1983.

27 SHAT, Commandement Supérieur des Forces en Algérie, Région Territoriale et Corps d'Armée d'Oran, État-Major, $2^{\text {ème }}$ Bureau, Étude sur l'OAS, 25 de mayo de 1962; Pierregot, Jerry de: Dictionnaire historique de l'OAS, Édition de l'auteur, Roubaix, 1990.

28 Kauffer: $O A S . .$. , págs. $422-423$.

29 Robin: Escadrons de la..., págs. 181-182.

30 Ésta es la sugestiva tesis de Daniel James; ver: James, Daniel: Resistencia e integración. El peronismo y la clase trabajadora argentina 1946-1976, Sudamericana, Buenos Aires, 1990. 
local ${ }^{31}$ lo cual implicaba no atacar su verdadera causa: las desigualdades sociales. Así, toda forma de oposición o protesta social pasó a ser interpretada como una manifestación de la penetración comunista en el país.

Con una larga tradición de acogida de perseguidos y desplazados, con sus matices europeos que generaban la ilusión de no estar en América latina, con sus cenáculos fuertemente excitados por la "inminencia" de una nueva conflagración mundial y con sus enormes espacios vacíos, la Argentina se ofrecía a estos derrotados del colonialismo tardío como un terreno promisorio para el olvido del pasado inmediato, para soñar con nuevas utopías autoritarias o recomenzar un camino interrumpido por las atrocidades del colonialismo francés. El cine y el policial negro se hicieron eco de esta cuestión. En el film Le combat dans l'île (de 1961, pero que debió esperar autorización de la censura hasta 1963) de Alain Cavalier, Jean-Louis Trintignant interpreta a un joven burgués desencantado que, después del fin de la guerra de Argelia, decide sumarse a un grupo de ultraderecha que planea varios atentados contra personalidades de izquierda. El grupo es traicionado por su jefe y sus acciones desbaratadas. Clément, el personaje de Trintignant, se encarga de ajusticiar al traidor (refugiado en Cádiz) y para cubrirse decide pasar una temporada en la Argentina. Al tiempo, cuando la situación se ha calmado, regresa a Francia y le cuenta su experiencia (en una granja de Entre Ríos) a su ex novia (interpretada por Romy Schneider): sólo son elogios para los "camaradas" que sin preguntar nada le han dado refugio, dinero, documentación falsa y lo han tratado de maravilla. El policial negro incorporó el contexto de la descolonización como escenario y sirvió como vía de reivindicación política de estos personajes. ${ }^{32}$

\section{La influencia francesa en el ámbito militar y católico a partir de 1955}

El ámbito castrense argentino era un terreno donde estas tendencias e ideas (anticomunismo y catolicismo tradicionalista), que explicaban el pre-

31 Rouquié, Alain: Poder militar y sociedad política en la Argentina, Tomo 2, Hyspamérica, Buenos Aires, 1986, págs. 156-159.

32 La lista completa no está hecha, y no es posible publicarla aquí. No obstante, mencionaremos: Les Murmures de la guerre, de Roger Ikor (Albin Michel, Paris, 1961), Jesús et ses aportes, de Camille Pilles (Paris, Julliard, 1973), Jean Hougron y su Mort en fraude (Club de la femme, 1961 laureado con el primer premio de la Académie Française) y Chaque homme est un drapeau, de Pierre Lantenac (Presses de la Cité, 1972). 
sente y proponían cursos de acción para el futuro inmediato coincidían, lo cual lo convertía en un espacio particularmente propicio para la inserción social de los recién llegados. Con la Guerra Fría y el derrocamiento de Perón, las Fuerzas Armadas y de Seguridad argentinas entraron en un proceso de renovación - tanto a nivel doctrinario como tecnológico-, además de exacerbar su tradicional politización. Los militares, bajo influencia de la doctrina de la guerra revolucionaria ${ }^{33}$ y luego de la doctrina de la seguridad nacional, pasaron a desempeñarse como policía política interna encargada de contrarrestar la "influencia comunista" y la "subversión", relegando a segundo plano su rol de brazo armado del Estado en la defensa exterior. La primera doctrina, de origen francés, había surgido de la derrota francesa en Indochina frente al Ejército Popular Norvietnamita. Un grupo de oficiales franceses, para no asumir su responsabilidad por el fracaso para reinstalar el control colonial, llegó a la conclusión de que enfrentaban un nuevo tipo de guerra, para el cual no estaban preparados. Ya no consistía en el clásico enfrentamiento entre fuerzas armadas por el control de un territorio y/o sus recursos económicos, sino que era un combate total que se libraba en el "corazón" y la "mente" de los habitantes: la guerra "moderna", "revolucionaria", o "subversiva", pero siempre de carácter "comunista" ${ }^{34}$ Esta doctrina presentaba el atractivo de ser un análisis totalizador, con el lenguaje propio de la Guerra Fría, pero que recuperaba varios temas tradicionales del imaginario militar argentino; además, se proponía como una explicación "científica" de la conflictividad social y como un curso de acción para un futuro cercano y sombrío. La segunda, resulta-

33 Amaral, Samuel: Guerra revolucionaria: de Argelia a la Argentina, 1957-1962, Academia Nacional de la Historia, Investigaciones y Ensayos 48, Buenos Aires, 1998, págs. 105-137; Mazzei, Daniel: "La misión militar francesa en la Escuela Superior de Guerra y los orígenes de la Guerra Sucia, 1957-1962", Revista de Ciencias Sociales, Universidad Nacional de Quilmes, 13, 1998, págs. 105-137.

34 La historiografía y la sociología militares están divididas en torno a la cuestión de la doctrina de la guerra revolucionaria: algunos la consideran el más importante aporte francés al pensamiento militar y otros lo consideran un fiasco intelectual y militar, que respondía a los intereses colonialistas de Francia. Para una visión amplia y crítica de la cuestión pueden consultarse: Dubreil-villatoux, Marie-Catherine, Villatoux, Paul: La guerre et l'action psychologiques en France (1945-1960), tesis de doctorado, Université Paris I Panthéon-Sorbonne, 2002; Géré, François: La pensée et la politique militaire françaises sous la quatrième République, de la guerre totale à la guerre révolutionnaire: conception et emploi de l'arme psychologique, tesis de doctorado, Université de Paris III, Paris, 1993; Périès, Gabriel: De l'action militaire à l'action politique. Impulsion, codification et application de la doctrine de la "guerre révolutionnaire" au sein de l'Armée française (1944-1960), tesis de doctorado, Université de Paris I, Paris, 1999; Shy, John, Collier, Thomas W.: "La Guerra Revolucionaria", en: Paret, Peter (dir.): Creadores de la estrategia moderna, desde Maquiavelo a la Era Nuclear, Ministerio de Defensa, Madrid, 1992. 
do de elaboraciones brasileñas y estadounidenses, incorporaba elementos de la doctrina francesa, pero otorgaba una importancia decisiva a la llamada "ayuda para el desarrollo", combinando represión y financiamiento en la investigación social y la tecnología.

En este contexto, una línea interna del Ejército encabezada por el entonces coronel Carlos Jorge Rosas intentó lograr cierta autonomía de decisión en lo militar. La estrategia imaginada por Rosas era buscar financiamiento y aprovisionamiento en Francia, para compensar la influencia estadounidense. Como resultado del accionar de varios oficiales superiores argentinos - entre ellos, los tenientes coroneles Alcides López Aufranc, Tomás Sánchez de Bustamante y Manrique M. Mom- y de parte de la representación diplomática francesa en la Argentina, las Fuerzas Armadas fueron introducidas en la doctrina militar francesa y se realizaron varios intentos para intensificar la presencia de la industria militar francesa en el mercado argentino..$^{35}$ Los contactos se incrementan a partir de la estadía del coronel Rosas en Francia (1953-1955 Superior de Guerra de París, lo cual fue el inicio de un importante intercambio de oficiales y asesores, el establecimiento de una misión militar francesa —en el Estado Mayor del Ejército y en la Escuela Superior de Guerra- y visitas al más alto nivel político y militar (como las del presidente Charles de Gaulle en 1964 y del jefe del Estado Mayor francés, general André Demetz, en mayo de 1960). ${ }^{37}$ La elaboración e instrumentación

35 García Lupo, Rogelio: "Indagaciones. Generales argentinos entre Francia y EE.UU.”, Clarín, Suplemento "Zona”, 22 de abril de 2001, pág. 7.

36 Antiperonista pero que se había negado a involucrarse en las conspiraciones para derrocar a Perón, Rosas fue designado por Decreto presidencial 14529 (7 de agosto de 1953) para cursar estudios en la Escuela Superior de Guerra de ese país. Cf. Ejército Argentino, Boletín Público del Ministerio de Ejército, Buenos Aires, 2504, 10 de agosto de 1953, pág. 978; Ejército Argentino, Dirección General del Personal, Archivo Histórico del Ejército, 15119, Rosas, Carlos Jorge (Ingenieros).

37 El rol del general Rosas en la "importación" de doctrina francesa es objeto de cierta controversia. Samuel Amaral, Rosendo Fraga, Daniel Mazzei, Diego Llumá y María Oliveira-Cézar le atribuyen la responsabilidad de introducir en el Ejército argentino de ideas y técnicas represivas utilizadas por los franceses en Indochina y Argelia. Por su parte, Rogelio García Lupo matiza esta impresión, a partir de sus vínculos personales con Rosas. Por otro lado, varios oficiales superiores contemporáneos de Rosas (Bignone, Reynaldo: Memoria y testimonio, Planeta, Buenos Aires, 1992, pág. 40; Genaro Díaz Bessone, Osiris Villegas, Albano Harguindeguy, entre otros) que han comentado este aspecto de la historia militar argentina coinciden en esta apreciación. En nuestra opinión, la trayectoria personal de Rosas debe ser tenida en cuenta en esta evaluación, por sobre sus estrechos vínculos con el Ejército francés. Basándonos en sus artículos publicados en la Revista de la Escuela Superior de Guerra, en la consulta de su archivo personal y en una entrevista con su hijo, pensamos que Rosas —un oficial atípico por su desapego a la religión católica, sus inquietudes intelectuales y su intento de resistir el golpe militar de 1966- no estaba tan interesado en la "doctrina de la guerra revolucionaria" como en 
del plan de seguridad interior denominado "Conmoción interna del Estado" (CONINTES) entre 1958-1960 y los reglamentos del Ejército argentino destinados a la lucha contra "fuerzas irregulares" y de operaciones contra la "subversión" (Reglamentos RC-8-2 [1968] y RC-8-3 [1969]) muestran la compenetración alcanzada entre los asesores franceses destacados en la Argentina y los oficiales argentinos.

Del lado argentino, se produjo en la misma época un muy importante auge editorial de la literatura católico-militar de origen francés, que se incorporaría a la bibliografía que circula y se estudia en los institutos argentinos de formación militar, como los libros del general Lionel-Max Chassin,$^{38}$ del propagandista tradicionalista católico Jean Ousset y del coronel Roger Trinquier ${ }^{39}$ sin olvidar la amplia difusión de la obra sobre estrategia del general André Beaufre (iniciada por el general Marini en 1954). Paralelamente, se aprecia una revitalización de la militancia de católicos tradicionalistas y de extrema derecha en los espacios de sociabilidad militares (institutos de formación, parroquias, asociaciones y grupos católicos laicos, etc.). En este sentido, la actividad de la Congregación de Cooperadores Parroquiales de Cristo Rey y del grupo "La Ciudad Católica", ambos de origen francés, es de vital importancia para completar, adaptar y legitimar el enfoque militar francés para el tratamiento de la conflictividad social. Auspiciados por monseñor Antonio Caggiano (cardenal primado de la Argentina), Ousset y su grupo "La Ciudad Católica" tuvieron una amplia difusión en el mundo castrense argentino. Los libros de

reorientar organizativa y tecnológicamente al Ejército, tomando distancia de la influencia estadounidense y estrechando los vínculos con Francia. Cf. Amaral, Samuel: Guerra revolucionaria: de Argelia a la Argentina, 1957-1962, Academia Nacional de, la Historia, Investigaciones y Ensayos 48, Buenos Aires, 1998, págs. 105-137; Fraga, Rosendo: Entrevista personal, 12 de agosto de 2004; García Lupo, Rogelio: "Indagaciones. Generales argentinos entre Francia y EE.UU.", Clarín, Suplemento "Zona”, 22 de abril de 2001; Llumá, Roberto Diego: Influence de la Mission d'assesseurs militaires français spécialistes en guerre contre révolutionnaire, dans la formation des officiers argentins pendant la période 1957-1970, Université de Paris III-Sorbone Nouvelle/Institut des Hautes Études de 1'Amérique latine, Memoria de DEA, Paris, 2003; MAZZEI, Daniel, "La misión militar francesa en la Escuela Superior de Guerra y los orígenes de la Guerra Sucia, 1957-1962", Revista de Ciencias Sociales, Universidad Nacional de Quilmes, 13, 1998, págs. 105-137; Oliveira-Cézar, María: "Las raíces francesas de la guerra antisubversiva", Todo es Historia, 422, Buenos Aires, septiembre de 2002, págs. 24-35; OliveiraCézar, María: "De los militares franceses de Indochina y Argelia a los militares argentinos de los años 50 y 60. El aprendizaje de la guerra contrarrevolucionaria", Todo es Historia, 435, Buenos Aires, octubre de 2003, págs. 70-80; Rosas, Carlos Diego: Entrevista personal, 14-15 de agosto de 2004; Rosas, General Carlos Jorge: Archivo personal, agosto de 2004.

38 Chassin, L. M.: La Conquista de la China por Mao Tsé-Tung, vol. 520, Círculo Militar, Biblioteca del Oficial, Buenos Aires, 1962.

39 La primera edición en castellano que encontramos fue la del Ejército Colombiano (Bogotá, Biblioteca del Ejército colombiano, Vol. 12, 1963). 
Ousset, como El Marxismo-leninismo. Introducción a la política (publicados por la Editorial Iction en 1963 y 1961, respectivamente) o Para que Él reine (traducido en 1962 por la Editorial Speiro en España, perteneciente a la filial local de "La Cité Catholique") y la revista Verbo aportarán un elemento crucial para el devenir del terrorismo de Estado en la Argentina: la tortura. Esta revista, de amplia circulación en el ámbito castrense entre 1966 y 1976, fue un baluarte de la justificación católica del uso de la tortura en prisioneros considerados "subversivos". ${ }^{40}$ Es un misterio para la historiografía el origen de este grupo en la Argentina. Por nuestra parte, hemos podido averiguar que surgió a principios de 1958 en torno al colaboracionista francés y presidente de los Cooperadores Parroquiales de Cristo Rey en la Argentina, Robert Pincemin y al ingeniero Mateo Roberto Gorostiaga, futuro secretario de Asistencia y Promoción de la Comunidad (1966-1967), repartición del Estado argentino especialmente creada por iniciativa de los hombres de "La Ciudad Católica". Pero lo más interesante es el rol de los sacerdotes de la Congregación de los Cooperadores Parroquiales de Cristo Rey, que llevarían a cabo numerosos retiros espirituales en unidades militares, en los cuales el principal tema de reflexión fue la preparación del militar católico para un baño de sangre que redimiría al país del inminente peligro comunista. Los miembros de esta congregación se preocuparon especialmente por la formación espiritual del personal militar, utilizando como método los ejercicios espirituales de San Ignacio de Loyola; sus vínculos con el Ejército son tan aceitados que llegan a organizar retiros espirituales para guarniciones enteras, ${ }^{41}$ como lo hacían habitual-

40 Los mejores ejemplos son: Cornelius, "Moral, derecho y guerra revolucionaria (I)", Verbo. Formación para la acción, 157, Buenos Aires, noviembre de 1975, Barbosa, Adalberto Zelmar (Director de la publicación, hoy responsable de Relaciones Internacionales de la Universidad Católica Argentina), "La Pena de Muerte y la Conciencia Universal", Verbo, 156, Buenos Aires, septiembre de 1975. El artículo firmado por Cornelius (seudónimo de Jean Ousset) es la traducción y adaptación del mismo trabajo publicado en 1958 para justificar el uso de la tortura por el Ejército francés para reprimir al movimiento independentista argelino; este artículo generó una fuerte polémica en la prensa francesa y colocó al grupo de Ousset al borde de la condena vaticana.

41 A partir de las informaciones obtenidas en las revistas oficiales de la Congregación de los Cooperadores en Francia y España, entre 1962 y 1969 sus sacerdotes oficiaron como conferenciantes y organizaron retiros espirituales, entre otros, en el Batallón $121^{\circ}$ de Rosario, en la base aérea de Villa Reynolds (San Luis), en el Batallón de Ingenieros de Corrientes y en la Base Naval de Puerto Belgrano. Cf. Sarat, R.P. Víctor: "En Amérique...", Marchons!, Saint-Bonnet-de-Valclerieux (Drôme), 329, junio 1964, pág. 238; "Programme du III ${ }^{\mathrm{C}}$ Congrès International de l'Euvre de Coopération Paraoissiale du Christ-Roi", Marchons !, Saint-Bonnet-de-Valclerieux (Drôme), 349, mayo 1966, pág. 159; Sarat, R.P. Víctor: "L'Euvre en Amérique du Sud", Marchons!, 341, septiembre 1965, pág. 232; "Marcha de la Obra en el mundo. Argentina", Avanzar, Madrid, Cooperación Parroquial de Cristo Rey, XXI, 239, julio 1965, págs. 230-231. 
mente en la España franquista. Uno de los integrantes de esta congregación, el sacerdote Georges Grasset, se convertió en una autoridad en la materia en la Argentina; miembro fundador también de "La Cité Catholique" francesa, fue reconocido en varias entrevistas como el líder de "La Ciudad Católica" argentina también conocido como "Grupo Verbo", el principal vehículo de la transmisión de ideas del tradicionalismo católico francés sobre la justificación católica de la tortura. Poco sabemos del rol del padre Grasset en este grupo, aunque en esa época se encontraba en la Argentina cumpliendo funciones en el capítulo local de su Congregación, los Cooperadores Parroquiales de Cristo Rey. ${ }^{42}$

Una "marea" de escritos, conferencias, charlas, cursos, grupos de estudios privados, publicaciones periódicas, "retiros espirituales" impulsados por "formadores" como el sacerdote Julio Meinvielle (líder del antisemitismo católico), Carlos Sacheri (presidente del grupo "La Ciudad católica" de la Argentina) y Jordán Bruno Genta (agitador enrolado en la extrema derecha católica) retomaban los temas y reproducían los análisis de los franceses. Estos "formadores" son sólo la "punta del iceberg" de un complejo entramado que conjugaba política y religión en un mismo análisis, responsable en gran medida de lo que el coronel Prudencio García definió como adoctrinamiento intensivo y formación reaccionaria y anticomunista. ${ }^{43} \mathrm{Su}$ principal aporte a la formación militar es consolidar el enfoque de los problemas políticos argentinos (especialmente, la violencia creciente, fruto de la proscripción del peronismo y de las desigualdades sociales) como el resultado de la "penetración" y de la "subversión" marxista que, como parte de una maniobra a escala planetaria, se abaten sobre la Argentina desde 1955.

Si bien la presencia de ex integrantes de la OAS en la Argentina ha sido señalada en diferentes fuentes y estudios, poco se sabe sobre su actividad concreta. En este sentido, se los menciona como instructores de técnicas de

42 Por razones de espacio, no podemos extendernos aquí sobre Grasset y "La Ciudad Católica". Nuestras informaciones provienen de Zuleta Álvarez, Enrique: Entrevista personal, Buenos Aires, 20 de mayo de 1999; Hernández, Héctor (Defensor Oficial, Juzgado Federal de Menores de San Nicolás de los Arroyos, provincia de Buenos Aires, y miembro de "La Ciudad Católica"), San Nicolás, 23 de julio de 2004; Brown, tte. cnel. Fabián (Jefe del Servicio Histórico del Ejército Argentino), Entrevista personal, Buenos Aires, 12 de agosto de 2004. Hemos hecho un seguimiento de esta actividad en la revista francesa (Marchons!) y la española (Avanzar) de la Congregación, conservadas en la Biblioteca Nacional de Francia y en la Biblioteca Nacional de España, respectivamente.

43 García, Prudencio: El drama de la autonomía militar. Argentina bajo las Juntas Militares, Alianza, Madrid, 1995. 
interrogatorio y contrainsurgencia $\mathrm{a}^{44} \mathrm{y}$ como parte de grupos paramilitares dedicados a reprimir a los disidentes a partir de $1973 .{ }^{45} \mathrm{El}$ periodista Marcelo Larraquy, sobre la base de testimonios directos que ha obtenido, sostiene que José López Rega (ex ministro de Bienestar Social, creador del grupo paramilitar, Alianza Anticomunista Argentina, y asistente personal de Perón) tenía una custodia compuesta por ex integrantes de la O.A.S, aunque no precisa su identidad. ${ }^{46}$

\section{Conclusión}

Hemos tratado una etapa de la presencia francesa en la Argentina como resultado de la pérdida de la colonia argelina, su contexto de inserción y la difusión de ideas de origen francés en los ámbitos militar y católico argentinos. Sin representar un aporte poblacional significativo, estos nuevos inmigrantes llegan a la Argentina en un momento de auge de la extrema derecha y de internacionalización de los conflictos locales para adaptarlos al esquema bipolar de la Guerra Fría. El aporte francés permite una actualización de ideas ya presentes en el imaginario de estos ámbitos para adaptarlos a la terminología y la ideología propias de la época. De este modo, las ideas francesas sobre la conflictividad social en el marco de la Guerra Fría se incorporarán a dos imaginarios históricamente ligados: el militar y el tradicionalista católico. Este aporte será de suma importancia para definir las técnicas e ideas que conformarán el terrorismo de Estado en la Argentina a partir de 1976.

44 Hodges, Donald: Argentina's “Dirty War”. An Intellectual Biography, Austin, University of Texas press, 1991, págs. 134-135. En otro registro, la novela News from a Foreign Country Came (New York, Clarkson Potter Publishers, 1991) de Alberto Manguel, cuenta la historia de un ex oficial del Ejército francés que reside en Québec, cuya historia personal une Argelia en la lucha por sacudirse el yugo colonial, el París de los sesenta y la Argentina de los desaparecidos, donde el personaje central ha ejercido sus habilidades como torturador, aprendidas durante su experiencia argelina.

45 Robin, Marie-Monique: Les escadrons de la mort: l'école française, Idéale Audience, documental, Paris, 2003. Robin retoma una reconstrucción de la masacre de Ezeiza (20 de junio de 1973) hecha por la revista montonera El Descamisado, reproducida por el diario Libération en julio de 1976. Nosotros, lamentablemente, no hemos podido corroborar esta información al cotejar otras fuentes secundarias y documentales.

46 Según los testimonios de ex miembros del círculo de colaboradores más cercanos del ex ministro y asistente personal de Perón recogidos por Larraquy, "en un viaje a Roma, López Rega había contratado a ex miembros de la OAS, que se hospedaban juntos en un hotel. Eran suboficiales y oficiales del Regimiento de Paracaidistas coloniales del Ejército Francés. [...] En la Argentina, la custodia argelina resguardaba la seguridad de algunos funcionarios ligados al ministro, entre ellos la del entonces presidente Raúl Lastiri. [...] Los ex OAS habían llegado a la Argentina con la promesa de que, tras un tiempo de actuar como gardes de corps, les cederían tierras en la provincia de Entre Ríos, donde crearían una colonia agrícola"; en: Larraquy, Marcelo: López Rega. La biografía, Editorial Sudamericana, Buenos Aires, 2003, págs. 235, 251. 
La circulación de personas y la transmisión de ideas se beneficiaron ampliamente tanto de la presencia histórica como del arribo - con la derrota del nazismo - de inmigrantes franceses que estuvieron dispuestos a ayudar a los compatriotas que huían de la justicia de su país. Esto también fue posible gracias a la complicidad y la lasitud de las autoridades argentinas para impedir la entrada de colaboracionistas del gobierno de Vichy y de terroristas de la OAS que llevaban graves condenas a cuestas; sin embargo, esta cuestión quedará sin dilucidar, hasta que los archivos franceses y argentinos sean más accesibles para el investigador. Por otra parte, el refugio que estas personas en fuga encontraron en la Argentina fue sujeto a las necesidades de política interna francesa, en momentos de alta conflictividad social como la liberación de Francia por las tropas aliadas o el fin de la guerra de Argelia, sumado a los acercamientos franco-argentinos a nivel institucional, como el establecimiento de una misión militar de asesoramiento en la Escuela Superior de Guerra de Buenos Aires y en el Estado Mayor del Ejército argentino. En la misma época, el activismo de grupos tradicionalistas católicos en el ámbito castrense regresa - como tantas otras veces-al centro de la escena. Los militares incorporaron a su enfoque de la conflictividad social y política argentina dos influencias francesas: por un lado, la proveniente de la doctrina de la guerra revolucionaria, o el conjunto de ideas que los militares franceses elaboraron para explicar su derrota en Indochina y la situación en Argelia; por otro lado, la interpretación tradicionalistacatólica de la Guerra Fría como enfrentamiento de civilizaciones. La fuerte impronta que dejaron estas dos influencias puede apreciarse en el discurso legitimador de la última dictadura militar argentina y en el rol desempeñado por algunos religiosos que, frente a las consultas de algunos oficiales, explicaron que los tormentos aplicados a los detenidos serían perdonados porque se practicaban en nombre de la defensa de la "civilización occidental y cristiana". ${ }^{47}$ Una poderosa batería compuesta por retiros espirituales, conferencias, cursos, grupos privados de estudio y reflexión hizo posible que los

47 El ex capitán de navío Adolfo Scilingo, procesado por el juez Garzón por genocidio, declaró que recibió "consuelo" de parte del capellán de la Escuela de Mecánica de la Armada, después de haber arrojado al Río de la Plata a prisioneros adormecidos desde un avión naval. Sobre el testimonio de Scilingo: véase Verbitsky, Horacio: El vuelo, Seix Barral, Barcelona, 1995, págs. 36-37; Mariano, Nilson: Operación Cóndor. Terrorismo de Estado en el Cono Sur, Ediciones Lohlé/Lumen, Buenos Aires, 1998, pág. 39. Podemos citar también el caso del teniente coronel Guillermo Enrique Bruno Laborda, actualmente detenido en la guarnición de Campo de Mayo por ser el primer oficial en actividad en declarar su participación en el asesinato de prisioneros indefensos durante la última dictadura; Cf. Verbitsky, Horacio: "Confesiones de un teniente coronel. Mancha venenosa", Página/12, Buenos Aires, 9 de junio de 2004. 
militares argentinos se convencieran de que cualquier método era lícito si se trataba de frenar el progreso de la "subversión comunista". Este esquema fue funcional a una histórica formación reaccionaria de las Fuerzas Armadas; en particular, sirvió para encuadrar bajo un esquema simplificador y totalizante todas las formas de protesta social que se derivaban de la proscripción del peronismo y del aumento de las desigualdades sociales. La formación en contrainsurgencia y la prédica del tradicionalismo católico (en especial, mediante los retiros espirituales) exacerbaron en el ámbito militar el temor a un cambio revolucionario y violento en la Argentina, lo que dio lugar a una respuesta salvaje y totalmente desproporcionada con relación a la supuesta "amenaza" que se cernía sobre la sociedad argentina.

Quisimos mostrar la coincidencia espacio-temporal de la llegada de personas e ideas desde Francia y cómo esto se sumó a un contexto particularmente crispado y proclive a creer en la existencia de un proceso de cambio social en ciernes, que debía ser extirpado de raíz, costara lo que costara, pues en ello iba el futuro de una sociedad argentina que se definía como "occidental y cristiana". La investigación en curso para nuestra tesis de doctorado nos induce a considerar esta coincidencia en términos de complementariedad e interacción, descartando la idea de causalidad en la construcción del terrorismo de Estado. Creemos que nuevas investigaciones sobre las raíces francesas del terrorismo de Estado en la Argentina podrán aportar seguramente nuevas pistas en torno a los orígenes y conformación no sólo en este país, sino en América del Sur, dada la importancia de la influencia militar y tradicionalista católica como en Perú, Colombia y ${ }^{48}$

48 En Perú, la Escuela Superior de Guerra fue creada y dirigida por oficiales franceses durante un largo período; por otro lado, la influencia francesa sobre el Ejército peruano se ejerció a través de la Escuela Superior de Guerra de Buenos Aires: como lo muestra Gabriel Périès en su tesis, el teniente coronel Bentresque (miembro de la misión militar francesa entre 1958 y 1960) junto con el general Anaya hicieron varias giras por Sudamérica para difundir la doctrina de la guerra revolucionaria; ver: Peries: De l'action militaire..., pág. 807. Además, la Escuela Superior de Guerra de Perú fue un destino habitual para los oficiales argentinos que hacían el curso de Estado Mayor; Cf. Boletín Reservado de la Secretaría de Guerra, 3798, Resolución del 6 de mayo de 1959, pág. 482. Consultando el programa del Curso GUENA de la Escuela Superior de Guerra Naval del Perú del año 2003, constatamos que la doctrina de la guerra revolucionaria francesa se sigue utilizando, esta vez como marco teórico para estudiar la lucha armada en ese país; ver: Marina de Guerra del Perú, Dirección de Instrucción, Escuela Superior de Guerra Naval, Curso GUENA, "Unidades formativas", 2003. Como mencionamos, el Ejército colombiano fue el primero en traducir al castellano el libro del coronel Roger Trinquier, $L a$ guerra moderna, el clásico francés sobre el uso de la tortura de prisioneros. Para el caso del Uruguay, se puede consultar el trabajo de Perilli, Carina: "From Counterrevolutionary Warfare To Political Awakening: The Uruguayan and Argentine Armed Forces in the 1970s", Armed Forces and Society, vol. 20, 1, 1993, págs. 25-49. 
ESQUEMA DE ANÁLISIS: CiRCULACIÓN DE PERSONAS E IDEAS:

FRANCIA-ARGENTINA, 1955-1966.

Referencias

CC La Cité Catholique (Francia, 1946-1963), La Ciudad Católica (Argentina, 1958).

CPCR Congregación de los Cooperadores Parroquiales de Cristo Rey. Francia (1934), España (1946), Argentina (1949).

RC-8-2 Reglamento del Ejército Argentino: Operaciones contra Fuerzas Irregulares, Tomos I, II y III (1968)

RC-8-3 Reglamento del Ejército Argentino: Operaciones contra la Subversión Urbana (1969)

M-10-1 Reglamento del Ejército Argentino: Procedimientos para las Operaciones contra la Subversión Urbana, (1972)

CONINTES Plan de Seguridad Interior (Conmoción Interna del Estado)

Recibido el 4 de enero de 2005 Aceptado el 5 de junio de 2005 
MARIO RANALETTI

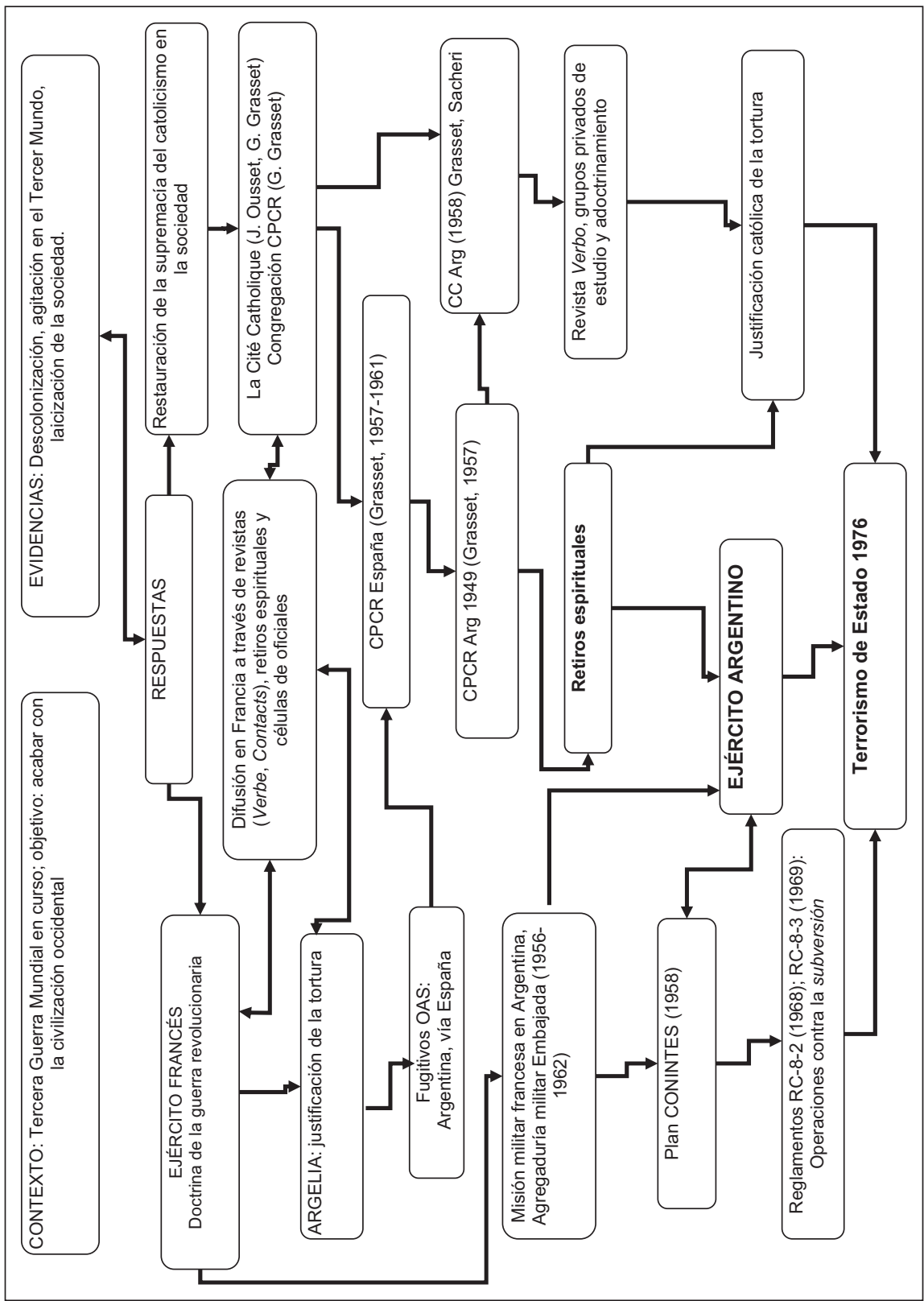

